\title{
Migrantes y trabajo forzado: enfoque normativo en México y tendencias jurisprudenciales en cortes regionales*
}

\author{
Migrants and forced Labor: Regulatory \\ approach in Mexico and Jurisprudential \\ trends in Regional Courts
}

Isaac de Paz González ${ }^{* *}$

María José Bernal Ballesteros***

\section{RESUMEN}

Este artículo tiene dos objetivos: conocer los ejes teóricos y normativos que protegen a los trabajadores migrantes en México y exponer criterios sobre el trabajo forzado en cortes constitucionales y regionales. La aportación significativa del artículo radica en mostrar que en México no hay una política nacional eficaz que proteja al migrante del trabajo forzado. No obstante, hay un desarrollo creciente de legislación nacional e instrumentos de protección internacionales que, a la par de distintas resoluciones, convergen en procedimientos civiles, penales y de derechos humanos que están construyendo lineamientos importantes para la erradicación del trabajo forzado de los migrantes como grupo vulnerable.

PALABRAS CLAVE: Migrantes, trabajo forzado, Corte Interamericana de Derechos Humanos, Brasil verde, Corte Europea.

\begin{abstract}
This article has two objectives: To recognize the theoretical and normative axes that protect migrant workers in Mexico and to expose criteria on forced labor in constitutional and regional courts. The significant contribution of the article lies in showing that in Mexico there is no effective national policy that protects the migrant from forced labor. However, there is a growing development of national legislation and international protection instruments that, together with different resolutions, converge on civil, criminal and human rights procedures that are building important guidelines for the eradication of forced labor of migrants as a vulnerable group.
\end{abstract}

KEY WORDS: Migrants, forced labor, InterAmerican Court of Human Rights.

\footnotetext{
* Artículo de investigación. Recibido el 30 de octubre de 2018 y aceptado para su publicación el 3 de septiembre de 2019.

** Profesor investigador de la Facultad de Derecho Tijuana, Universidad Autónoma de Baja California, México. (isaac.depaz@uabc.edu.mx) orcid.org/0000-0002-2267-5629

*** Profesora en la Facultad de Derecho de la Universidad Autónoma del Estado de México. (majo.ballesteros07@ gmail.com) orcid.org/0000-0001-6090-8457
} 


\section{SUMARIO}

1. Enfoque teórico y normativo del trabajo forzado

2. Fallas de origen por la creciente presión del flujo migratorio

3. Los enfoques jurisprudenciales regionales

4. Las aportaciones de las cortes nacionales: Estados Unidos e Inglaterra

5. La falta de jurisprudencia en México

6. Conclusiones

\section{Enfoque teórico y normativo del trabajo forzado}

El origen del problema migratorio se atribuye a la inseguridad, los contextos de violencia, el cambio climático, los desastres ecológicos, las desigualdades sociales, la reunificación familiar y la falta de oportunidades que, particularmente, padecen las personas del sur global. Las situaciones a las que los migrantes están expuestos durante el traslado y la llegada a sus destinos representan un alto riesgo para su integridad y la de sus familiares. Aunado a ello, una vez instalados en alguna ciudad o punto fronterizo comienzan a padecer exclusión social y laboral, así como discriminación, lo cual los convierte en un grupo altamente vulnerable. En este contexto, el presente trabajo de investigación se enfocará en mostrar los elementos normativos de los trabajadores migrantes y los mecanismos de garantía de sus derechos, así como los enfoques jurisprudenciales de tribunales regionales de derechos humanos.

La metodología del trabajo se basó en la revisión de los cuerpos normativos nacionales e internacionales para conocer los derechos de los trabajadores migrantes en el contexto de México y con referencias a Centroamérica. Asimismo, se sondearon las cifras del trabajo forzado a nivel internacional y nacional, con datos de la Organización Internacional del Trabajo (огт), de la Organización de las Naciones Unidas (onU), así como de organizaciones que han estudiado el fenómeno en América Latina. El objetivo de esta revisión empírica fue determinar que, a pesar de la universalidad de los derechos de los migrantes, cada región presenta problemas distintos; también se advierte que las políticas públicas para enfrentar el tema son diversas, en los ámbitos internacional, regional y nacional. En la parte final del trabajo se muestran los avances de los tribunales regionales en materia de trabajo forzado como un elemento integrador que debe ser retomado en las jurisdicciones domésticas para lograr un cambio de enfoque de política migratoria, pero también de otras líneas de política pública que inciden en el trabajo forzado. 
El origen moderno del trabajo forzado como concepto jurídico universal proviene del sistema internacional de derechos humanos. En la antigüedad, la esclavitud estuvo permitida. Fue hasta el siglo xvIII cuando comenzaron los procesos abolicionistas en Europa, los cuales se consolidaron hasta el siglo xx en el resto del mundo. Distintos jueces constitucionales tuvieron intervención relevante para prohibir la esclavitud. Uno de ellos fue Lord Mansfield, en el caso Somerset vs. Stewart: mediante un habeas corpus, Somerset fue liberado de su amo (Stewart), quien lo pretendía trasladar de Londres a las plantaciones de azúcar en Jamaica. La sentencia adujo que aunque en las colonias el comercio de esclavos era legal, no lo era en Inglaterra, pues para esta última, la esclavitud es algo inmoral y la libertad es un derecho natural, inalienable e ilimitable, especialmente cuando se trata de hombres libres y cristianos. ${ }^{1}$ Para algunos, el caso Somerset aceleró la guerra de independencia, debido al temor de perder la fuerza productiva de los esclavos de las colonias por la inminente abolición. ${ }^{2}$

En 1926 surgió el primer cuerpo normativo: la Convención sobre la esclavitud de 1926, emitida por la Liga de las Naciones, que tajantemente prohibía la comercialización de seres humanos:

A los fines de la presente Convención se entiende que: 1. La esclavitud es el estado o condición de un individuo sobre el cual se ejercitan los atributos del derecho de propiedad o algunos de ellos; 2. La trata de esclavos comprende todo acto de captura, adquisición o cesión de un individuo para venderle o cambiarle; todo acto de cesión por venta o cambio de un esclavo, adquirido para venderle o cambiarle, y en general todo acto de comercio o de transporte de esclavos.

Poco después, en 1930, se emitió el Convenio 29 sobre Trabajo Forzoso de la orr. En este cuerpo normativo, se define como el trabajo exigido mediante la amenaza y la coacción al individuo (trabajador), esto es, "todo trabajo o servicio exigido a un individuo bajo la amenaza de una pena cualquiera y para el cual dicho individuo no se ofrece voluntariamente" (artículo 2).

Luego se retomó el concepto con más amplitud en el Convenio 105 de la огт (1957) sobre la abolición del trabajo forzoso. En las décadas de la Segunda Guerra Mundial, y un poco después, la valoración normativa del trabajo forzado

\footnotetext{
${ }^{1}$ King's Bench Court, Somerset v. Stewart, Londres, Trinity Term, 22 de junio, 1772.

2 WeBb, Derek, "The Somerset effect: Parsing Lord Manfield's. Words on Slavery in Nineteenth-Century America", Law and History Review, vol. 32, núm. 3, p. 459.
} 
tomó fuerza en la India y África en el contexto de las luchas de independencia y la supresión de la explotación laboral colonialista. ${ }^{3}$

En 1999, la orT elaboró la Convención 182 sobre las peores formas de trabajo forzado infantil, con el objeto de crear un marco conceptual para prevenir y sancionar la venta de menores, su reclutamiento para la guerra o los conflictos armados, su explotación sexual en diversos ámbitos y su utilización en actividades ilícitas, como el tráfico de drogas. Cabe mencionar que el Convenio solo abarca menores de 16 años, y establece rangos de edades para trabajadores de menos de 12 años. Estos preceptos se leen en consonancia con el artículo 32 de la Convención de los Derechos del Niño, que prohíbe toda forma de explotación en su contra.

A pesar de la existencia de un marco jurídico internacional, desde el inicio del siglo xx, los marcos nacionales no necesariamente califican el trabajo forzado ni la esclavitud moderna como conductas penales o sancionables en el ámbito civil. Esto se debe probablemente a que los avances significativos han sido desde el derecho penal internacional, cuando se definieron los elementos típicos de la conducta de esclavitud ante la Corte Penal Internacional en el caso del fiscal $v s$. Kunarac. ${ }^{4}$ Sin embargo, los estudios sobre las diferencias entre servidumbre, esclavitud y trabajo esclavo establecen la importancia de que las legislaciones nacionales prevean mecanismos legales distintos para castigar las tres conductas en distintos ámbitos. ${ }^{5}$ Los estudios más avanzados, por su parte, notan la problemática de las medidas de reparación y satisfacción de las víctimas de esclavitud moderna.

Para autores de contextos donde la esclavitud moderna es un tema de interés público con intenso escrutinio judicial, el problema es multidimensional, pues no sólo abarca cuestiones de justicia penal, sino de política pública integral $y$, en consecuencia, la esclavitud y el trabajo forzado demandan una estrecha y permanente colaboración entre agentes estatales, empresas, grupos de derechos humanos y agencias internacionales. ${ }^{6}$ En consecuencia, el sistema europeo ${ }^{7}$ ha formulado directivas amplias para la prevención del trabajo forzado y se

\footnotetext{
${ }^{3}$ Véase SwEPSTON, LEE, "Forced and Compulsory Labour in International Human Rights Law", working paper, Suiza, International Labour Organization, 2014, pp. 10-12.

${ }^{4}$ Corrie, Karen, "Could the International Criminal Court Strategically Prosecute Modern Day Slavery?", Journal of International Criminal Justice, vol. 14, núm. 2, p. 302.

${ }^{5}$ Vladislava, Stoyanova, Conceptual Limits and States' Positive Obligations in European Law, Human Trafficking and Slavery Reconsidered, Cambridge, Cambridge University Press, 2017, p. 294.

${ }^{6}$ Gardner, Alison, "An Idea Whose Time Has Come? Modern Slavery, Multiple Streams Approach and Multilayer Policy Implementation", Journal of Human Rights Practice, núm. 10, pp. 461-481.

7 Véase European Commission, "Sustainable and responsible supply chains", European Comission. [Consulta: 23 de agosto, 2019]. Disponible en: https://ec.europa.eu/europeaid/sectors/economic-growth/private-sector-development/ sustainable-and-responsible-supply-chains_en
} 
han creado normas en torno a la explotación laboral o esclavitud que tienen múltiples procedimientos punitivos, financieros y de política de producción, ${ }^{8}$ a través del control y la revisión de las cadenas de suministro. Esto ha sido gradual y ha tomado fuerza desde la vinculación de las empresas (como entes responsables de proteger y ejercer acciones positivas con el medio ambiente) para prevenir violaciones de derechos humanos en todos sus procesos adquisitivos, de producción y venta de productos libres de trabajo forzado. ${ }^{9}$ Por lo tanto, en adición a las leyes migratorias, el entorno de vulnerabilidad de los trabajadores migrantes está relacionado con los "factores económicos, políticos y socioculturales que, ligados a su identidad e historia [...] pueden limitar su capacidad para responder a efectos adversos; lo cual no se restringe a la falta de satisfacción de necesidades materiales, sino también a conductas que discriminan y estigmatizan". ${ }^{10}$

Para efectos vinculantes de los tratados que conforman el marco legal internacional del trabajo forzado en nuestro país, México ha ratificado los siguientes: Convención relativa a la esclavitud y su protocolo de modificación (Diario Oficial de la Federación 11 de mayo de 1955); Convenio 29 de la Organización Internacional del Trabajo (огт) sobre el Trabajo Forzoso (Dof, 13 de agosto de 1935); Convenio 105 de la orT sobre la Abolición del Trabajo Forzoso (DOF, 21 de agosto de 1959); Convenio 182 sobre las peores formas de trabajo infantil de la orT (DOF, 7 de marzo de 2001), Protocolo para Prevenir, Reprimir y Sancionar la Trata de Personas, especialmente Mujeres y Niños, que complementa la Convención de las Naciones Unidas contra la Delincuencia Organizada Trasnacional (DOF, 10 de abril de 2003). Como veremos más adelante, este marco ha servido de piso mínimo para crear las normas nacionales sobre trabajo forzado.

Respecto a las cifras globales del trabajo forzado, diversas organizaciones han señalado la existencia de varios subtipos de trabajo forzado y explotación humana en las siguientes actividades: matrimonio forzado, explotación en el trabajo doméstico, trabajo forzado en fábricas, agricultura y actividades marítimas, explotación sexual, esclavitud moderna en cadenas de suministro y tráfico de personas con los propósitos de explotación. La definición actual más completa

\footnotetext{
${ }^{8}$ Hay paises como el Reino Unido que han creado toda una legislación y un órgano de control para revisar la adecuación de la cadena de suministro que vigila las prácticas de las empresas para evitar el trabajo esclavo en cualquiera de sus fases de producción. Véase: Home Secretary, "Transparency in Supply Chains etc. A practical guide 2017", Home Secretary. [Consulta: 14 de agosto, 2018]. Disponible en: https://assets.publishing.service. gov.uk/government/uploads/system/uploads/attachment_data/file/649906/Transparency_in_Supply_Chains_A_ Practical_Guide_2017.pdf

${ }^{9}$ ONu, Principios Rectores sobre las Empresas y los Derechos Humanos, Ginebra, onu, 2011, p. 2.

${ }^{10}$ Delgado Carbajal, Baruch y Bernal Ballesteros, Maria José, Catálogo para la calificación de violaciones a derechos humanos, Toluca, Comisión de Derechos Humanos del Estado de México, 2016, pp. 43-44.
} 
es la que emite el Protocolo para Prevenir, Reprimir y Sancionar la Trata de Personas, especialmente Mujeres y Niños, que complementa la Convención de las Naciones Unidas contra la Delincuencia Organizada Transnacional. En su artículo 3, señala:

Por trata de personas se entenderá la captación, el transporte, el traslado, la acogida o la recepción de personas, recurriendo a la amenaza o al uso de la fuerza u otras formas de coacción, al rapto, al fraude, al engaño, al abuso de poder o de una situación de vulnerabilidad o a la concesión o recepción de pagos o beneficios para obtener el consentimiento de una persona que tenga autoridad sobre otra, con fines de explotación. Esa explotación incluirá, como mínimo, la explotación de la prostitución ajena u otras formas de explotación sexual, los trabajos o servicios forzados, la esclavitud o las prácticas análogas a la esclavitud, la servidumbre o la extracción de órganos.

El exrelator especial sobre los derechos humanos de los migrantes del Consejo de Derechos Humanos de las Naciones Unidas (CDHNU) ha referido que "cuando los canales regulares de migración no reflejan adecuadamente las necesidades del mercado de trabajo, los migrantes tienen más probabilidades de que las redes de tráfico ilícito de personas y los contratantes poco éticos les ofrezcan soluciones de migración irregular, y de pasar a ser víctimas de la explotación y los abusos". ${ }^{11}$ de ahí que sea de suma importancia la existencia de políticas públicas y normatividad que regule de manera integral la migración.

Según cifras de diversas organizaciones, aproximadamente "40 millones de personas en el mundo son víctimas de la esclavitud moderna en 2016, y 152 millones de niños entre 5 y 17 años están en situación de trabajo infantil. La orT presentó además un informe asociado que confirma que alrededor de 152 millones de niños, entre 5 y 17 años, son víctimas del trabajo infantil". ${ }^{12}$ En toda América, hay aproximadamente 2 millones de personas bajo condición de esclavitud moderna y se aporta aproximadamente con 5\% de la población mundial. En el análisis que realizó Global Slavery Index, Venezuela, Haití y la República Dominicana fueron los países con mayor prevalencia de la esclavitud moderna; sin embargo, Estados Unidos, Brasil y México tuvieron los números

\footnotetext{
${ }^{11}$ Consejo de Derechos Humanos de las Naciones Unidas (CDHNU), "Informe del Relator Especial sobre los derechos humanos de los migrantes sobre una agenda 2035 para facilitar la movilidad humana A/HRC/35/25", 28 de abril, 2017, párr. 31.

${ }^{12}$ oIT (Organización Internacional del Trabajo), "Esclavitud moderna y trabajo infantil", disponible en: https://www.lo. org/global/about-the-ilo/newsroom/news/WCMS_574731/lang--es/index.htm [Consulta: 4 de octubre, 2018].
} 
absolutos más altos y representaron más de la mitad (57\%) de las víctimas en la región. ${ }^{13}$ Los estudios sobre la trata de personas muestran que el origen del problema tiene que ver con la inequidad social ${ }^{14} \mathrm{y}$ también con la capacidad trasnacional de las organizaciones criminales que someten a personas de países pobres a la explotación laboral y sexual, generalmente.

Frente a las cifras actuales de trabajo forzado, las agendas internacionales coinciden en que los mecanismos preventivos y represivos deben ser asequibles a las personas que padecen una situación de explotación, para que sus derechos sean resarcidos. El primer problema al que se enfrentan es a la falta de vinculación estatal a favor de las normas que protegen a los migrantes como ciudadanos con plenos derechos. El aspecto que referíamos al inicio, relacionado con la soberanía de cada Estado, conlleva a que la normatividad internacional permita limitar el acceso a ciertos derechos en función del estatus de la persona y, en este sentido, se entiende que no están obligados a extender sus derechos políticos a los extranjeros, tal es el caso del derecho a casarse, el derecho a votar o a presentarse a puestos electivos, así como el derecho al trabajo. ${ }^{15}$

En general, los derechos laborales de los migrantes están dispuestos, mediante las políticas migratorias de un Estado que se establecen mediante actos, medidas $\mathrm{u}$ omisiones institucionales que regulan la entrada, la salida o la permanencia de las personas nacionales y extranjeras dentro de sus territorios. No obstante, esos actos regulados por leyes, decretos, actos administrativos y de otra naturaleza deberán ser siempre compatibles con las normas de protección de los derechos humanos y, por tanto, no pueden ser discriminatorios. Sin embargo, la discrecionalidad que tienen los Estados para emitir sus políticas migratorias no puede ser entendida como una justificación para cometer actos $u$ omisiones que atenten contra la dignidad, las libertades y los derechos humanos de los migrantes; la calidad migratoria de una persona no puede suponer una trasgresión o limitación del goce de sus derechos. La persona migrante, al asumir una relación de trabajo, adquiere una serie de derechos laborales que deben ser respetados y garantizados por el Estado, como el empleo en igualdad de condiciones ante el resto de los trabajadores y con independencia de su estatus

\footnotetext{
${ }^{13}$ Global Slavery Index, "Americas Report 2018", Global Slavery Index. [Consulta: 14 de agosto, 2018]. Disponible en: https://www.globalslaveryindex.org/2018/findings/regional-analysis/americas/

${ }^{14}$ Ripoll, AlejandRa, "Colombia: Semillero para la trata de personas", Revista de relaciones internacionales, estrategia y seguridad, vol. 3, núm. 1, pp. 175-186.

${ }^{15}$ Oficina del Alto Comisionado de Naciones Unidas y Tribunal Superior de Justicia del Distrito Federal, Derecho Internacional de los Derechos Humanos: normatividad, jurisprudencia y doctrina de los Sistemas Universal e Interamericano, México, Alto Comisionado de Naciones Unidas - Tribunal Superior de Justicia del Distrito Federal, 2012, p. 953.
} 
migratorio; es decir, que dichas prerrogativas le sean otorgadas como consecuencia de su relación laboral.

El Estado tiene la obligación de evitar y sancionar situaciones de discriminación en las relaciones laborales que se creen entre los particulares y las personas extranjeras o migrantes, así como de que dicha relación contractual considere los estándares mínimos internacionales. Dicha responsabilidad debe ir más allá, pues supone, además, que el Estado garantice los medios adecuados para ejercer sus derechos laborales, incluyendo los de los trabajadores migrantes indocumentados. ${ }^{16}$

\section{Fallas de origen por la creciente presión del flujo migratorio}

El trabajo forzado existe en México, Brasil y otros países latinoamericanos. Los factores suelen ser variables: por deudas, por matrimonio y por explotación laboral. ${ }^{17}$ La Comisión Interamericana de Derechos Humanos (CIDH) ha detectado trabajo esclavo en el chaco boliviano en contra de comunidades indígenas. A pesar de la existencia de normas que prohíben el trabajo forzado y la ratificación del Convenio 182 por parte del Estado boliviano y otras prácticas violatorias de derechos humanos, la CIDH detectó que las víctimas no tuvieron acceso a la justicia por su situación de vulnerabilidad. ${ }^{18}$

Ahora bien, el grupo que interesa para efectos de este trabajo son los migrantes en México. Un primer problema detectado es la ausencia de registros confiables del número de personas que ingresaron por la frontera sur a México en los últimos cinco años. Debido a la migración en masa (caravanas), el registro se ha vuelto un tema complicado, pues esta situación los coloca en un estado de extrema peligrosidad al viajar dentro del territorio a razón de la violencia del crimen organizado.

México contempla la protección amplia como personas con plenos derechos de acuerdo con el artículo 1 constitucional y, en particular, de conformidad con la Ley de Migración a través de diversas categorías, tales como migrantes 212 en situación de vulnerabilidad (asilado, refugiado, menores). En su artículo 3, también se prevé garantía de su derecho al trabajo, pues la fracción XxV señala que la remuneración consiste en: "las percepciones que reciban las

\footnotetext{
${ }^{16}$ Silva Garcia, Fernando, Jurisprudencia Interamericana sobre Derechos Humanos. Criterios esenciales, México, Tirant lo Blanch, 2016, pp. 869 y 870.

${ }^{17}$ oाт (Organización Internacional del Trabajo), "Estimación Mundial sobre el trabajo infantil y la esclavitud moderna de 2017. Hoja de Datos Regional de las Américas", Ginebra, olr, 2017, p. 5.

${ }^{18}$ OEA (Organization of American States), Captive communities: situation of the Guarani indigenous people and contemporary forms of slavery in the Bolivian Chaco, OEA, 24 de diciembre, 2009.
} 
personas en el territorio de los Estados Unidos Mexicanos por la prestación de un servicio personal subordinado o por la prestación de un servicio profesional independiente". Sin embargo, la realidad económica del desempleo en México impone restricciones de facto para que a los migrantes se les facilite hallar un trabajo digno.

En estas condiciones, el ámbito laboral es un campo fértil donde se aprovecha la falta de regulación y se permite la explotación. Ante la carencia de documentos migratorios, los migrantes están expuestos a situaciones de discriminación, explotación laboral y violencia, pues al no tener otra posibilidad de acceder a un empleo formal, deben conformarse y aceptar las condiciones indignas que les ofrecen como indocumentados. Así, el punto central de la negación a los derechos de los migrantes reside en el trabajo de los migrantes, concatenado con el comportamiento ascendente de los flujos de personas que ingresaron a México de Centroamérica desde 2005 y hasta $2019 .{ }^{19}$ En consecuencia, el problema de imponer medidas de prevención al trabajo forzado de migrantes aumenta por la falta de garantías de proceso en torno a los derechos laborales y políticos. ${ }^{20}$

Por otra parte, y como norma especial, México cuenta con la Ley General para Prevenir, Sancionar y Erradicar los Delitos en materia de Trata de Personas y para la Protección y Asistencia a las Víctimas (2012), que tipifica las conductas de esclavitud, explotación laboral, servidumbre y matrimonio forzado. De acuerdo con los artículos 1, 10, 21 y 22 de dicha normatividad, el trabajo forzado tiene como elementos las condiciones insalubres, la ilicitud, la desproporción y el salario por debajo del mínimo legal. A este marco debemos añadir el Protocolo para Prevenir, Reprimir y Sancionar la Trata de Personas, especialmente Mujeres y Niños, que señala la misma defınición más amplia en materia de trata de personas prevista en la Convención de las Naciones Unidas contra la Delincuencia Organizada Transnacional.

Como normas especiales, a partir de 2017, México implementó el Protocolo de Actuación para Prevenir el Trabajo Forzado y llevar a cabo revisiones administrativas en diversos sectores laborales. El Protocolo de Inspección para Prevenir y Detectar la Trata de Personas en los Centros de Trabajo ${ }^{21}$ toma como referencia la Ley General para Prevenir, Sancionar y Erradicar los Delitos en

\footnotetext{
${ }^{19}$ Así se advierte en oIm (onu Migración), "Reporte de flujos migratorios en Centroamérica, Norteamérica y el Caribe no. 6", San José de Costa Rica, oım. [Consulta: 23 de agosto, 2019]. Disponible en: https://reliefweb.int/sites/reliefweb. int/files/resources/SITREP\%206\%20-\%20espanol\%20-\%20web.pdf

${ }^{20}$ Situación que también en Europa pone en jaque a los sistemas nacionales.

${ }^{21}$ Secretaría del Trabajo y Previsión Social, "Protocolo de Inspección para Prevenir y Detectar la Trata de personas en los Centros de Trabajo", México, Secretaria del Trabajo y Previsión Social, 2017. [Consulta: 23 de agosto, 2019]. Disponible en: https://www.gob.mx/cms/uploads/attachment/file/200998/Protocolo_Trata_en_centros_de_trabajo.pdf
} 
materia de Trata de Personas y Para la Protección y Asistencia a las Víctimas de estos Delitos y el Reglamento Federal de Seguridad y Salud en el Trabajo, para definir siete situaciones de explotación laboral: trata de personas, explotación, explotación laboral, violencia laboral, labores peligrosas o insalubres y servicios (de salud e higiene) al personal. Existe también el Protocolo de Inspección del Trabajo en materia de Erradicación del Trabajo infantil y Protección al Trabajo adolescente permitido (2012). Si bien son protocolos generales, ninguno de estos hace alusión a los lineamientos especiales cuando se detecten migrantes, tanto adultos como menores, que sufran explotación laboral.

Por otra parte, el mapa de la migración nacional y la recepción de migrantes en México han cambiado debido a la política de militarización de la frontera $\operatorname{sur}^{22}$ y a la alta incidencia de eventos delictivos que se intensifica en contra de los migrantes en el país. Por ello, el caso de México es sui generis; hay dos fenómenos en torno a los derechos laborales de los migrantes: aquellos que son deportados y que aceptaban condiciones laborales de explotación y alta vulnerabilidad y los que llegan de otros países en su paso hacia Estados Unidos de América.

Para entender la ausencia de vías de protección laboral, tanto en el plano legislativo como de política pública y de acceso a la justicia a favor de los migrantes que llegan a México. Una reforma que impacta en la violación de los derechos laborales del migrante y que provoca ausencia de registros confiables de trabajadores es el outsourcing. ${ }^{23}$ Dentro de este contexto, Ruiz Moreno señala implícitamente que hay dos marcos regulatorios, uno para los trabajadores migrantes que entran de manera legal a México y otro para los inmigrantes irregulares que tienen, como todo ser humano, un elemental derecho a la vida y a la asistencia sanitaria, a no ser torturado o sometido a castigos degradantes, a no prestar trabajo forzoso y a no ser detenido arbitrariamente. ${ }^{24}$ El sistema mexicano de protección a los migrantes en materia laboral mantiene un hermetismo total. Es muy difícil que un extranjero que llega sin documentos a México pueda confrontar el abuso laboral, bajo condiciones de igualdad, pues el acceso a la justicia es de por sí escueto para los trabajadores mexicanos. Posiblemente, esta falta de acceso a los recursos judiciales ha permitido que

\footnotetext{
${ }^{22}$ WiLIINSON, DanieL, "México desplegará su Guardia Nacional para enfrentar a familias migrantes", Human Rights Watch. [Consulta: 23 de agosto, 2019]. Disponible en: https://www.hrw.org/es/news/2019/06/12/mexico-desplegara-suguardia-nacional-para-enfrentar-familias-migrantes

${ }^{23}$ Reforma del artículo 15-A de la Ley Federal del Trabajo, vigente a partir de diciembre de 2012. Dicha reforma empeoró los derechos de los trabajadores y le quitó responsabilidad en materia de seguridad social y contribuciones a las empresas.

${ }^{24}$ Ruiz Moreno, Ángel Guillermo, "El derecho humano al trabajo de los migrantes", Revista Latinoamericana de Derecho Social, vol. 22, p. 215.
} 
las cifras de trabajo forzado y otras formas de explotación humana en México se incrementen.

En el Reporte de Trata 2019 de la Comisión Nacional de Derechos Humanos ( $\mathrm{CNDH})$ se establece que entre 2017 y 2018 el Instituto Nacional de Migración (INM) detectó 133 víctimas (63 de Honduras, 29 de Guatemala, y en menor cantidad de El Salvador, Venezuela, Colombia, España, Cuba, Italia y Uruguay). "La dependencia indicó que 78 personas fueron [víctimas] de trata en la modalidad de explotación sexual (73 mujeres y cinco hombres), 52 en la modalidad de explotación en los trabajos forzados (35 mujeres y 17 hombres) y tres en mendicidad forzada (dos mujeres y un hombre)." ${ }^{25}$ Esta es la única cifra más o menos confiable sobre migrantes que han sufrido explotación de algún tipo y ello obedece a que el diagnóstico de la CNDH fue elaborado tomando en cuenta cifras de procuradurías y del INM.

En parte, uno de los temas pendientes es que las entidades federativas cuentan con mecanismos especiales de prevención y protección de migrantes. Los factores pueden ser de diversa índole. Los más comunes son que la migración es un tema de jurisdicción federal y no es competencia de los ayuntamientos ni de las autoridades estatales. Si a ello se añade que:

A julio de 2017, solo 16 congresos locales habían realizado una armonización legislativa a la Ley General: Aguascalientes, Baja California, Colima, Coahuila, Ciudad de México, Durango, Guerrero, Estado de México, Jalisco, Puebla, Querétaro, Tamaulipas, Veracruz, Zacatecas, Quintana Roo y Michoacán. La armonización significó que habían emitido una nueva Ley o reformado su Ley expresamente para armonizarla con la Ley General, y derogaron el tipo penal de sus códigos o éstos remiten a la Ley General. Entre los Congresos que no habían realizado una armonización legislativa con la Ley General se encuentran los siguientes: Baja California Sur, Chiapas, Nayarit, Nuevo León y Morelos. Campeche y Chihuahua, Guanajuato, presentaron reformas a su Código, pero no habían emitido una nueva Ley o reformado su Ley expresamente para armonizarla con la Ley General: Tlaxcala y San Luis Potosí. ${ }^{26}$

\footnotetext{
${ }^{25}$ Comisión Nacional de Derechos Humanos, Diagnóstico sobre la situación de la Trata de Personas en México, México, Comisión Nacional de Derechos Humanos, 2019, p. 273.

${ }^{26}$ Comisión Nacional de Derechos Humanos, Diagnóstico sobre la situación de la Trata de Personas en México, México, Comisión Nacional de Derechos Humanos, 2019, p. 16.
} 
En consecuencia, el panorama es problemático. Ante la falta de inclusión legislativa de mecanismos normativos preventivos y reparadores, el avance es muy lento y solo es verificable a nivel federación. De acuerdo con el Departamento de Estado de los Estados Unidos, México no cumple con los estándares mínimos de protección y prevención de delitos de trata de personas, dentro de los que se incluye el trabajo forzado. Lo que en particular detecta la agencia de Estados Unidos es una serie de desconexiones entre normas, política pública y ejecución de las normas. Por ejemplo, señala que no hay una base de datos de migrantes explotados, que hay poca capacitación en el Poder Judicial para este tipo de delitos, y que el número de procesos es bueno, pero el número de sentenciados es bajo en comparación con las acciones iniciadas. ${ }^{27}$ Por ejemplo, el reporte advierte que:

Las autoridades iniciaron acciones judiciales contra 510 personas en casos federales y estatales en 2018, en comparación con 609 personas en casos federales y estatales en 2017; 479, en 2016 y, 578, en 2015. Las autoridades condenaron a 60 tratantes involucrados en 25 casos federales y 35 estatales, en comparación con 95 tratantes involucrados en 40 federales y estatales casos en 2017, 228 tratantes involucrados en 127 casos federales y estatales, en 2016 y, 86 tratantes involucrados en 36 casos federales y estatales en $2015 .^{28}$

En otros rubros, el reporte menciona que los mecanismos de protección especial y asistencia a víctimas siguen siendo muy escasos. Aunque hay avances en la cooperación de agencias interestatales, no hay un política nacional homogénea en el tema que unifique la operación de albergues (públicos y privados), el registro de víctimas, las cantidades de asistencia monetaria que se les pueden dar y el tratamiento especial a menores. ${ }^{29}$ En materia de prevención, tampoco existe un trabajo coordinado entre el INM, la Secretaría del Trabajo federal y sus pares locales. Por lo tanto, se puede deducir que el problema de la transgresión a los derechos de los migrantes y su explotación laboral no

\footnotetext{
${ }^{27}$ Embajada y Consulado de los Estados Unidos en México, "Reporte sobre Trata de Personas 2019, Recomendaciones priorizadas", US Embassy. [Consulta: 23 de agosto, 2019]. Disponible en: https://mx.usembassy.gov/es/ourrelationship-es/reportes-oficiales/reporte-sobre-trafico-de-personas/

${ }^{28}$ Embajada y Consulado de los Estados Unidos en México, "Reporte sobre Trata de Personas 2019, Recomendaciones priorizadas", US Embassy. [Consulta: 23 de agosto, 2019]. Disponible en: https://mx.usembassy.gov/es/ourrelationship-es/reportes-oficiales/reporte-sobre-trafico-de-personas/

${ }^{29}$ Embajada y Consulado de los Estados Unidos en México, "Reporte sobre Trata de Personas 2019, Recomendaciones priorizadas", US Embassy. [Consulta: 23 de agosto, 2019]. Disponible en: https://mx.usembassy.gov/es/ourrelationship-es/reportes-oficiales/reporte-sobre-trafico-de-personas/
} 
es un tema exclusivamente de vacíos normativos, sino de la ausencia de una política pública sectorizada de acuerdo con el nivel de competencia de cada autoridad que interviene, donde se incluyan a todos los actores: organizaciones de la sociedad civil, defensorias estatales y municipales de derechos humanos, secretarías de estado del ámbito laboral (que apliquen sus protocolos en materia de revisión), y que se difunda el enfoque de los derechos humanos en el sector privado, industrial y comercial.

Para concluir este apartado, diremos que debido a la ineficacia de cumplimiento y resultado de las regulaciones laborales y la demanda de mano de obra barata -mayormente auspiciadas en ciudades industriales como la periferia de la Ciudad de México y otras ciudades industriales y fronterizas como Tijuana, en las que se han establecido-, según cifras de la cNDH, hay al menos 20000 migrantes, en su mayoria haitianos y sudamericanos, de 2016 a 2018.

\section{Los enfoques jurisprudenciales regionales}

A falta de una serie de lineamientos, tanto sustantivos como procesales, para proteger integralmente los derechos humanos de los migrantes en México, consideramos pertinente que este trabajo ofrezca un panorama de soluciones desde la jurisdicción de los derechos humanos sobre el trabajo forzado. Como ya se advirtió en la primera parte de este trabajo, la explotación de los grupos en vulnerabilidad no es tema que respete ámbitos geográficos. Por ello, acudiremos al sistema regional europeo para analizar las tendencias existentes.

El sistema regional europeo mantiene una protección amplia de los derechos de los migrantes para evitar su explotación laboral. La Convención Europea de Derechos Humanos establece, en su artículo 4, las prohibiciones del trabajo esclavo y forzado: "1. Nadie podrá ser sometido a esclavitud o servidumbre. 2. Nadie podrá ser constreñido a realizar un trabajo forzado u obligatorio". ${ }^{30}$ La definición de esclavitud que ha establecido el Tribunal Europeo de Derechos Humanos (TEDH) estipula que la esclavitud es la condición que se ejerce sobre una persona alguna o todas las condiciones del derecho de propiedad. ${ }^{31}$

Los principios de interpretación del artículo 4 se armonizan con el derecho internacional. En el caso Ranstev vs. Chipre y Rusia, el Tribunal estableció que las provisiones del artículo 4 y el conjunto del Convenio debe tratarse como instrumento para la protección de los seres humanos individuales. Exige que

\footnotetext{
${ }^{30}$ Aprobada por el Consejo de Europa en la Ciudad de Roma, el 4 de noviembre de 1950.

${ }^{31}$ TEDH (Tribunal Europeo de Derechos Humanos), Siliadin v. France (Application no. 73316/01), Sentencia del 26 de octubre de 2005.
} 
sus disposiciones se interpreten y apliquen de manera que sus salvaguardas sean prácticas y eficaces. ${ }^{32}$ Además, dentro del marco de protección, se dijo que la trata de personas y su explotación atenta contra la dignidad humana, y que ello no es compatible con los valores que se defienden en una sociedad democrática y que son parte del Convenio. ${ }^{33}$ Así, el Tribunal, habida cuenta de su obligación de interpretar el Convenio a la luz de condiciones actuales, considera innecesario identificar, en el contexto específico de trata, ya sea que el tratamiento del que se queja el solicitante constituya "esclavitud", "servidumbre" o "trabajo forzado y obligatorio" y considera que el propio tráfico está previsto en otras disposiciones que se deben aplicar en armonía con el artículo 4 del Convenio. ${ }^{34}$

Un caso reciente en Europa fue Chowdury y otros vs. Grecia. Los hechos dan cuenta de un grupo de trabajadores originarios de Bangladesh que fueron reclutados bajo el engaño de un trabajo (cosecha de fresas) bien pagado con derecho a residencia europea. Desde luego, los trabajadores llegaron sin los permisos debidos a finales de 2012 y sus empleadores no pagaron los salarios de los solicitantes y los obligaron a trabajar en condiciones físicas difíciles bajo la supervisión de guardias armados. Los demandantes alegaron haber sido sometidos a trabajo forzoso. Asimismo, afirmaron que el Estado tenía la obligación de impedir que fueran víctimas de la trata de personas, adoptar medidas preventivas con ese fin y castigar a los empleadores.

El TEDH sostuvo que Grecia violó, en perjuicio de los quejosos, las disposiciones previstas en el artículo 4.2 del Convenio, al considerar que los solicitantes no habían recibido una protección efectiva ni el acceso a la justicia. Uno de los aspectos que, a nuestro modo de ver, nos parece de suma importancia es la utilización del derecho internacional multinivel, esto comprende la Convención de Ginebra sobre la Esclavitud de 1926, el Convenio del Consejo de Europa de Lucha contra la Trata de Seres Humanos (en vigor desde 2014) y el Protocolo de Palermo (2000). ${ }^{35}$ Asimismo, el TEDH observó que la situación de los demandantes era de trata de personas y trabajo forzoso, y especificó que la explotación a través del trabajo era uno de los aspectos de la trata de seres humanos. El Tribunal también encontró que el Estado no había cumplido

\footnotetext{
${ }^{32}$ TEDH (Tribunal Europeo de Derechos Humanos), Rantsev v. Chipre \& Rusia (Application no. 25965/04), sentencia del 7 de enero, 2010.

${ }^{33}$ TEDH (Tribunal Europeo de Derechos Humanos), Rantsev v. Chipre \& Rusia (Application no. 25965/04), sentencia del 7 de enero, 2010, párr. 282.

${ }^{34}$ TEDH (Tribunal Europeo de Derechos Humanos), Rantsev v. Chipre \&t Rusia (Application no. 25965/04), sentencia del 7 de enero, 2010.

${ }^{35}$ TEDH (Tribunal Europeo de Derechos Humanos), Chowdury y otros vs. Grecia (Application no. 21884/15), sentencia del 30 de marzo, 2017, párrs. 37-39.
} 
con sus obligaciones de prevenir la situación de la trata de personas, de proteger a las víctimas, de llevar a cabo una investigación efectiva de los delitos cometidos y de castigar a los responsables de la trata. ${ }^{36}$

Uno de los avances más notables del sistema europeo es la obligación que impone su corpus iuris para que los Estados tomen medidas adicionales en todos los ámbitos de su competencia. En el caso C. N. vs. Reino Unido se estableció que el artículo 4 del Convenio impone medidas operacionales, de acuerdo con los hechos de cada caso, para evitar que se repitan (lo que en el sistema interamericano llamamos "efecto útil"). En este sentido, el TEDH estableció que las autoridades estatales conocían, o deberían conocer, las circunstancias dando lugar a una sospecha creíble de que una persona identificada había sido o era sometida a un tratamiento que infringía el artículo 4 del Convenio. En el caso de una respuesta afirmativa, habrá una violación de ese artículo cuando las autoridades no tomen las medidas apropiadas dentro del alcance de sus poderes para remover al individuo de esa situación o riesgo. ${ }^{37}$

Ante la escalada de llegada masiva de inmigrantes del Medio Oriente y de África subsahariana, Europa se halla en la encrucijada de crear, a corto plazo, soluciones que eviten la explotación de migrantes bajo esquemas que no sólo son de negación de derechos laborales, sino que corren el grave peligro de ser capturados por el crimen organizado, pues al negar derechos civiles y laborales, los inmigrantes pueden ser sujetos de "explotación para realizar actividades delictivas" de grupos criminales que los instigan al carterismo, hurtos en comercios, tráfico de estupefacientes y otras actividades similares que están castigadas con penas e implican una ganancia económica. ${ }^{38}$

El sistema interamericano ha propuesto una serie de políticas públicas y medidas generales para que los Estados puedan adecuar sus marcos legislativos a las obligaciones que se derivan del artículo 6 de la Convención Americana de Derechos Humanos, que señala la prohibición de la esclavitud y la servidumbre en todas sus formas. Junto al artículo, el esquema normativo del sistema interamericano parte de la discriminación como categoría amplia de protección en todos los sentidos: a) político, desde las normas nacionales de prevención y reparación; y b) procesal, mediante la sanción de conductas de explotación laboral dentro de los sistemas nacionales. También se han

\footnotetext{
${ }^{36}$ TEDH (Tribunal Europeo de Derechos Humanos), Chowdury y otros vs. Grecia (Application no. 21884/15), sentencia del 30 de marzo, 2017, párrs. 12, 123 y 128.

${ }^{37}$ TEDH (Tribunal Europeo de Derechos Humanos), C.N. vs. Reino Unido (Application no. 4239/08), sentencia del 13 de febrero, 2013, párrs. 68, 79, 80.

38"Directiva 2011/36/UE del Parlamento Europeo y del Consejo de 5 abril de 2011", Diario Oficial de la Unión Europea. [Consulta: 22 de julio, 2018]. Disponible en: https://eur-lex.europa.eu/legal-content/ES/TXT/PDF/?uri=CELEX:3201 1 L0036\&tfrom $=\mathrm{HU}$
} 
asociado los derechos de los migrantes a la dimensión de los derechos sociales y en favor de los derechos civiles en conexión con otros derechos, tal como quedó demostrado en los casos de las niñas Yean y Bosico vs. República Dominicana (2005) y el caso de los Dominicanos-Haitianos expulsados vs. República Dominicana (2014).

La explotación laboral de los migrantes en los Estados miembro del Pacto de San José es un hecho notorio y perjudicial en todos los sentidos. Por una parte, en sus informes temáticos, la ciDH ha descubierto la gravedad de la explotación de personas en Brasil, Perú, Centroamérica y, sobre todo, en México. En su informe respectivo, la ciDH señala que, en su visita a México, esta Comisión obtuvo información correspondiente a hombres migrantes forzados a trabajar en distintas formas para grupos de la delincuencia organizada, mientras se encuentran secuestrados. ${ }^{39}$

Ante la gravedad del asunto, la CIDH ha hecho hincapié en la urgencia de que los Estados adopten medidas más contundentes en el problema de la explotación humana, mediante el deber de prevenir, investigar, procesar y sancionar, así como el deber de adoptar disposiciones de derecho interno (que incluye derogar aquellas que sean contrarias a las normas protectoras). ${ }^{40}$ La obligación que resulta más relevante es la de prevenir, pues "abarca todas aquellas medidas de carácter jurídico, político, administrativo y cultural que promuevan la salvaguarda de los derechos humanos y que aseguren que las eventuales violaciones de los mismos sean efectivamente consideradas y tratadas como un hecho ilícito". ${ }^{41}$

La Corte Interamericana de Derechos Humanos (Corte IDH) ha sostenido que el término discriminación hace referencia a "toda exclusión restricción o privilegio que no sea objetivo o razonable, que redunde en detrimento de los derechos humanos". ${ }^{42}$ Mientras que la CIDH, en el Caso Interdicción de haitianos,

\footnotetext{
${ }^{39} \mathrm{CIDH}$ (Comisión Interamericana de Derechos Humanos), "Derechos humanos de migrantes, refugiados, apátridas, víctimas de trata de personas y desplazados internos: Normas y Estándares del Sistema Interamericano de Derechos Humanos", 2015. [Consulta: 24 de septiembre, 2018]. Disponible en: http://www.oas.org/es/cidh/informes/pdfs/ movilidadhumana.pdf

${ }^{40} \mathrm{CIDH}$ (Comisión Interamericana de Derechos Humanos), "Derechos humanos de migrantes, refugiados, apátridas, víctimas de trata de personas y desplazados internos: Normas y Estándares del Sistema Interamericano de Derechos Humanos", 2015, párr. 179. [Consulta: 24 de septiembre, 2018]. Disponible en: http://www.oas.org/es/cidh/informes/ pdfs/movilidadhumana.pdf

${ }^{41} \mathrm{CIDH}$ (Comisión Interamericana de Derechos Humanos), "Derechos humanos de migrantes, refugiados, apátridas, víctimas de trata de personas y desplazados internos: Normas y Estándares del Sistema Interamericano de Derechos Humanos", 2015, párr. 155. [Consulta: 24 de septiembre, 2018]. Disponible en: http://www.oas.org/es/cidh/informes/ pdfs/movilidadhumana.pdf

${ }^{42}$ Corte IDH (Corte Interamericana de Derechos Humanos), Opinión Consultiva OC-18/03, Condición jurídica y derechos de los migrantes indocumentados, serie A, núm. 18, 17 de septiembre, 2003, párr. 83.
} 
entendió a la discriminación como "una diferenciación irrazonable en lo que se refiere al tratamiento de personas de la misma clase o categoría". ${ }^{43}$

En materia laboral, la Corte IDH ha dejado en claro que si bien es cierto que los Estados y los particulares de un Estado no están obligados a contratar o brindarles una fuente de trabajo a los migrantes indocumentados, cuando exista una relación laboral, entonces se generan todos los efectos jurídicos, quedando obligados a respetar los estándares internacionales antes referidos. ${ }^{44}$ No obstante, con la adopción de una dimensión más amplia de las obligaciones convencionales sobre trabajo esclavo y mecanismos de protección, el sistema interamericano ha dado un paso mayúsculo en la lucha contra este crimen.

En este aspecto, la jurisprudencia interamericana permite hacer una reflexión más amplia sobre las obligaciones de los particulares, no sólo en materia de derechos civiles, sino en materia de derechos económicos, sociales y culturales. Recordemos que la responsabilidad de los particulares no ha sido plenamente tratada por la Corte IDH. No obstante, la jurisprudencia sí ha determinado que "la atribución de responsabilidad al Estado por actos de particulares puede darse cuando el Estado incumple, por acción u omisión de sus agentes, esta función de protección, pero sólo en aquellas circunstancias particulares en las que se considere que los agentes estatales cumplían una posición de garantes en relación con la acción de particulares". En este sentido, la obligación primaria del Estado es evitar las violaciones de derechos humanos y eso incluye a los gobernados. La aportación que aquí podemos enmarcar es que el sistema interamericano tiene un potencial formante en las jurisdicciones y políticas públicas domésticas para que los Estados impulsen medidas más amplias de respeto a los derechos humanos, especialmente a quienes se hallan en una situación de vulnerabilidad inherente a su condición migratoria, de género, étnico o por la simple discriminación económica. ${ }^{45}$

El caso Hacienda Brasil verde $v$ s. Brasil (2016) es un referente regional sobre la concepción multidimensional y sistemática del derecho internacional de los derechos humanos y las obligaciones positivas que cada Estado debe adoptar para detener la explotación humana sobre sus congéneres. Por primera vez, el Tribunal Interamericano se pronuncia sobre la violación al artículo 6 del Pacto de San José y enjuicia a un Estado por permitir condiciones de explotación

\footnotetext{
${ }^{43} \mathrm{CIDH}$ (Comisión Interamericana de Derechos Humanos), "Informe N 51/96. Decisión de la Comisión en cuanto al mérito del caso 10.675", 13 de marzo de 1997, párr. 178.

${ }^{44}$ Morales Sánchez, Juleta, Derechos de los migrantes en el Sistema Interamericano de Derechos Humanos, México, Comisión Nacional de los Derechos Humanos, 2015, p. 57.

${ }^{45}$ Debe decirse que la Corte IDH se ajusta al marco universal de los derechos humanos con un enfoque multidimensional de todos los tratados de derechos civiles y políticos, económicos, y los comentarios generales del Comité Desc, así como los principios sobre pobreza extrema y derechos humanos.
} 
inhumana y trabajo esclavo. Además, en su voto razonado, el juez Eduardo Ferrer Mac-Gregor perfiló un nuevo enfoque de la discriminación económica como categoría justiciable.

En primer lugar, el caso se refiere a hombres que eran esclavos en las plantaciones de Brasil. Un elemento jurídico que toma relevancia en el caso es el contexto histórico de exclusión, discriminación y pobreza que padecieron las víctimas, ya que "los trabajadores, en su mayoría hombres jóvenes, analfabetos y pobres"; "afrodescendientes que son reclutados para trabajar en Estados alejados, con la promesa de salarios atractivos”. Al llegar a las haciendas, bajo vigilancia de hombres armados, "los trabajadores son informados de que están en deuda con sus contratistas por su transporte, alimentación y hospedaje. Los salarios prometidos son reducidos y no cubren los costos ya asumidos". ${ }^{46}$

Los hechos del caso dan cuenta de cómo dos trabajadores heridos y bajo amenazas de muerte lograron huir de una hacienda enclavada en el corazón de la Amazonía. A la postre, dan cuenta a la policía federal, quien realizó una inspección y liberó a todos los trabajadores, por lo que se iniciaron los procedimientos administrativos y penales para aplicar las sanciones correspondientes. Sin embargo, Brasil no garantizó el derecho de acceso a la justicia ni la reparación adecuada, por lo que el asunto se elevó al sistema interamericano.

La aportación que realiza la Corte IDH para los sistemas nacionales de derechos humanos es la vinculación al marco universal y la definición de trabajo esclavo, dentro del contexto de sometimiento por una relación de poder de un individuo sobre otro. Los dos elementos que la Corte considera "fundamentales para definir una situación como esclavitud son: I) el estado o condición de un individuo y II) el ejercicio de alguno de los atributos del derecho de propiedad, es decir, que el esclavizador ejerza poder o control sobre la persona esclavizada al punto de anular la personalidad de la víctima". ${ }^{47}$ Para construir la decisión e imponer las medidas pertinentes a Brasil, la Corte siguió los lineamientos dispuestos por la Corte Penal Internacional en el tribunal para Yugoslavia, Fiscal vs. Kunarac, en cuya sentencia se describieron los siguientes elementos:

a) restricción o control de la autonomía individual; b) pérdida o restricción de la libertad de movimiento de una persona; c) la obtención de un provecho por parte del perpetrador; $d$ ) la ausencia de consentimiento o de libre albedrío de la víctima, o su imposibilidad o irrelevancia debido

\footnotetext{
${ }^{46}$ Corte IDH (Corte Interamericana de Derechos Humanos), Hacienda Brasil verde vs. Brasil, Excepciones Preliminares, Fondo, Reparaciones y Costas, Serie C, núm. 318, Sentencia de 20 de octubre, 2016, párr. 269.

${ }^{47}$ Corte IDH (Corte Interamericana de Derechos Humanos), Hacienda Brasil verde vs. Brasil, Excepciones Preliminares, Fondo, Reparaciones y Costas, Serie C, núm. 318, Sentencia de 20 de octubre, 2016, párr. 269.
} 
a la amenaza de uso de la violencia u otras formas de coerción, el miedo de violencia, el engaño o las falsas promesas; e) el uso de violencia física o psicológica; $f$ ) la posición de vulnerabilidad de la víctima; $g$ ) la detención o cautiverio, i) la explotación. ${ }^{48}$

La acepción construida por la Corte IDH al tomar el marco jurisprudencial internacional es una muestra de la universalización del corpus iuris de derechos humanos y de la interpretación horizontal de todos los tratados en la materia. La intención de la Corte fue dotar de contenido al artículo 6 del Pacto de San José.

De los resolutivos de la sentencia Brasil Verde se desprende una pedagogía novedosa sobre el tratamiento para asuntos de discriminación estructural que contiene tres directrices: la primera es que se alude a una situación histórica de discriminación que padecen las personas más débiles en un sistema social: los campesinos que no han tenido ningún acceso a la alfabetización y, por ende, son fácilmente engañados. La segunda es que la Corte IDH logró una interpretación evolutiva sobre la discriminación, pues se pone el dedo en la llaga de la pobreza como posible forma de discriminación jurídicamente reprochable. El juez Ferrer-Mac-Gregor señaló que:

No puede pasar inadvertido para un juez interamericano que la esclavitud, en sus formas análogas y contemporáneas, tiene un origen y consecuencia en la pobreza, la inequidad y la exclusión social, repercutiendo en las democracias sustantivas de los países de la región. De este modo, el análisis de la experiencia interamericana de protección de derechos humanos (civiles, políticos, económicos, sociales, culturales y ambientales) demanda que sean consideradas las peculiaridades de la región, ya que América Latina es la región con el más alto grado de desigualdad en el mundo. En ese sentido, los Estados en la región deben ser consecuentes con lo que proclama la Carta Social de las Américas (2012) y su Plan de Acción (2015) para procurar y lograr progresivamente la realización plena de la justicia social en nuestro continente.

En este aspecto, se esperaría que los jueces nacionales, en el tratamiento jurídico de los derechos laborales, especialmente de grupos vulnerables, tengan en consideración el contexto histórico y no sólo construyan la decisión judicial

\footnotetext{
${ }^{48}$ Corte IDH (Corte Interamericana de Derechos Humanos), Hacienda Brasil verde vs. Brasil, Excepciones Preliminares,
} Fondo, Reparaciones y Costas, Serie C, núm. 318, Sentencia de 20 de octubre, 2016, párr. 272. 
sostenida en una tipología de derechos, sino que hagan valer todo el bloque de derechos que más favorezca en la situación concreta. En tercer lugar, la Corte IDH establece la obligación de Brasil para cumplir con sus obligaciones previstas en el artículo 7 del Convenio 182 de la orт para prevenir las formas de trabajo y explotación infantil que obliga a los Estados a:

a) impedir la ocupación de niños en las peores formas de trabajo infantil; b) prestar la asistencia directa necesaria y adecuada para librar a los niños de las peores formas de trabajo infantil y asegurar su rehabilitación e inserción social; c) asegurar a todos los niños que hayan sido librados de las peores formas de trabajo infantil el acceso a la enseñanza básica gratuita y, cuando sea posible y adecuado, a la formación profesional; $d$ ) identificar a los niños que están particularmente expuestos a riesgos y entrar en contacto directo con ellos, y e) tener en cuenta la situación particular de las niñas.

Un cuarto elemento fundamental del asunto Hacienda Brasil Verde vs. Brasil fue su enfoque sobre el cambio de políticas públicas, de legislación y de revisiones administrativas para lograr la erradicación del trabajo esclavo en Brasil. A partir del 2000, las autoridades brasileñas, poco a poco, crearon planes, directrices, instituciones, y medidas económicas para erradicar el trabajo esclavo: el Grupo Especial de Fiscalización Móvil, dentro del ámbito de la Secretaría de Fiscalización del Trabajo del Ministerio del Trabajo, con atribuciones para actuar en el medio rural e investigar denuncias de trabajo esclavo; la Coordinadora Nacional de Erradicación del Trabajo Esclavo que presentó el Primer Plan Nacional de Erradicación del Trabajo Esclavo; el establecimiento de tipos penales especiales y tribunales sobre trabajo esclavo, así como la creación de medidas financieras y económicas para evitar que empleadores de trabajadores esclavos accedieran a recursos públicos. ${ }^{49}$

Sin lugar a dudas, la jurisprudencia interamericana propone un enfoque estructural para erradicar el trabajo esclavo, con lo cual se construyen estructuras in situ. Es necesario reconocer que los marcos domésticos son los más adecuados para enfrentar los graves problemas de violaciones a los derechos humanos. Aunque las víctimas en el caso de Brasil Verde no eran inmigrantes, analógicamente, se trata de un grupo marginado que debe ser protegido con mayor intensidad. Ahora bien, las soluciones y los programas instaurados

${ }^{49}$ Corte IDH (Corte Interamericana de Derechos Humanos), Hacienda Brasil verde vs. Brasil, Excepciones Preliminares, Fondo, Reparaciones y Costas, Serie C, núm. 318, Sentencia de 20 de octubre, 2016, párr. 469. 
por Brasil no solo beneficiarian a los trabajadores nacionales, sino que, eventualmente, crearían un marco resiliente de acceso al trabajo con controles y mecanismos de rendición de cuentas para aquellos particulares que abusen de su posición de poder.

\section{Las aportaciones de las cortes nacionales: Estados Unidos e Inglaterra}

La evidencia empírica de la jurisprudencia en cortes nacionales sugiere que la esclavitud y el trabajo forzoso se refieren tanto a comportamientos castigados en virtud de los procedimientos de derecho civil, procesos penales y, posiblemente, en asuntos estrictamente constitucionales. Uno de los asuntos más técnicos es el de las obligaciones extracontractuales por pago de daños provenientes de acciones ilícitas. En Estados Unidos, por ejemplo, después de la devastación del huracán Katrina, con falsas promesas de inmigración legal y basada en el trabajo, un grupo de hombres de origen hindú fueron traídos para brindar servicios en Mississippi y Orange (Texas). Una vez en suelo americano, los trabajadores fueron sometidos a trabajo forzado. La empresa contratante y sus agentes amenazaban con coaccionar a los trabajadores para que siguieran prestando sus servicios en condiciones ilegales, de violencia verbal, amenazas y de alto riesgo. Bajo el esquema de fraude (ley civil), los trabajadores indios obtuvieron una compensación en una serie de acuerdos en las etapas iniciales de los juicios.

La protección a los derechos laborales de los migrantes en Estados Unidos ha sido una constante lucha por la inclusión desde diversas perspectivas: como parte de la no discriminación y del debido proceso y el acceso a la justicia. En la Suprema Corte de Estados Unidos se presentó un conundrum: ¿puede un extranjero ilegal tener derecho al trabajo sin tener derecho a estar dentro de Estados Unidos? ¿Puede tener derecho a una licencia de conducir, ya que cada Estado puede asignar ciertas prerrogativas y oficialmente se tolera su presencia en Estados Unidos ${ }^{50}$ La pregunta no ha sido respondida, pues la Suprema Corte rechazó la petición de fondo para que sea resuelta por la Corte de Distrito y se determine si el Gobierno federal violó la Ley federal del procedimiento administrativo, al pretender instaurar deportaciones masivas. ${ }^{51}$ En este sentido, los argumentos principales estuvieron sustentados en la crisis

\footnotetext{
${ }^{50}$ US Supreme Court, United States et al. vs. Texas et al., caso 15-674. Argumentos orales del 18 de abril, 2016, intervención del Juez Alito.

${ }^{51}$ US Supreme Court, United States et al. vs. Texas et al., caso 15-674. Argumentos orales del 18 de abril, 2016, intervención del Juez Alito.
} 
humanitaria que puede provocar una deportación masiva y la inexistencia de recursos económicos y materiales para llevar a cabo tal acción.

Inglaterra es uno de los países que tiene una regulación más activa y eficiente para prevenir los abusos de derechos humanos por parte de los particulares. A través de la legislación creada en 2015, el Parlamento Británico estableció cinco directrices:

Medidas preventivas contra una persona o entidad empresarial; Crea un sistema de revisión contra la trata de personas en territorios, fronteras y puertos; se crea un fiscal y comisionado de Estado contra el trabajo esclavo con amplias facultades de investigación y reportes; se crea la comisión que velará por la transparencia en las cadenas de suministro de toda organización comercial a la que se le pedirá un reporte anual sobre sus acciones preventivas en: cualquier parte de su cadena de producción, suministro y venta; en las medidas apropiadas de educación y entrenamiento en sus equipos de trabajo y en sus expresiones comerciales y mensajes de internet.

En virtud de ello, en el Reino Unido, los delitos de esclavitud y trata de personas se toman en serio. En 2017, la Corte Suprema emitió una sentencia histórica que permitió a dos mujeres de Filipinas e Indonesia, traídas con engaños como empleadas domésticas de una diplomática extranjera, presentar sus reclamaciones ante un tribunal laboral. Al principio, se alegó la falta de acción y derecho, debido a su condición migratoria, pero este argumento fue desechado. La sentencia señaló tres aspectos: a) la importancia de la explotación laboral de los inmigrantes por los diplomáticos; b) ninguno de los actos tomados por el diplomático en relación con sus empleados domésticos fueron actos realizados en el ejercicio de sus funciones; y c) "la universalidad de la determinación de la comunidad internacional para combatir la trata de personas". ${ }^{52}$ En otras partes de Inglaterra, los tribunales inferiores han emitido juicios importantes contra los traficantes y propietarios de empresas en los que los jueces tomaron el asunto como un interés público, debido a la vulnerabilidad de las víctimas. Tal es el caso de un grupo de víctimas (18 hombres) discapacitados y en situación de calle que fueron raptados para ser sometidos a condiciones de explotación laboral. ${ }^{53}$

\footnotetext{
52 The Supreme Court of the United Kingdom, Reyes v. Al-Malki and another [2017] UKSC 61, párrs. 55, 59, 60.

${ }^{53}$ Nottingham Crown Court, Case T20167397, (12 September 2017), (the Rooney family case).
} 


\section{La falta de jurisprudencia en México}

En México no existen casos relevantes sobre explotación laboral, en especial de migrantes. Eso no quiere decir que no suceda, ni que se dé por hecho que existe un acceso a la justicia de personas que son sujetas a violaciones graves de sus derechos laborales. Desafortunadamente, los migrantes en México sufren de violaciones graves en contra de su libertad y de su vida. Así lo demuestran los informes de la CNDH que han señalado diversas zonas del país que son inhóspitas para los migrantes en tránsito desde Sudamérica. ${ }^{54}$ Por otro lado, se afirma que México sirve de paso y almacén para el tráfico de migrantes tanto nacionales como extranjeros. Se pone énfasis en tres ejes: crecimiento de la delincuencia organizada y el aumento de los factores, tanto de expulsión como de atracción. ${ }^{55}$ Sin embargo, la débil protección en materia laboral que se otorga a nacionales en el contexto de la jurisdicción laboral es un factor que explica la carente protección a migrantes.

De acuerdo con Martínez Quezada y Ortega Ramírez, en su estudio de la frontera sur, a pesar de la reforma de derechos humanos de 2011, la legislación y las acciones gubernamentales en Chiapas han sido omisas: se "mantiene la política de criminalizar, ilegalizar (detener y deportar) la internación de migrantes con los consabidos abusos, maltratos y trato indigno en su contra". ${ }^{56}$ La ausencia de decisiones judiciales importantes en materia de explotación laboral sólo puede explicarse mediante un análisis de las normas de procedimiento previstas en la Ley Federal del Trabajo, pues solo aplican a trabajadores formales, sin que se haga valer algún mecanismo de protección a favor de migrantes que son víctimas de explotación material laboral. De tal modo, no es posible conocer la dinámica jurisprudencial de los derechos laborales en México a favor de los migrantes.

Los pronunciamientos que se han emitido dentro de la jurisdicción penal versan sobre explotación sexual, y no se cuenta con legislación especializada para monitorear el trabajo forzado de migrantes ni con cuerpos administrativos que verifiquen la existencia (o no) de esclavitud o trabajo forzado en la

\footnotetext{
${ }^{54}$ Según el informe de la cNDH, en el sur del pais, fueron secuestrados 5416 migrantes (55\%); en el norte, 981 (11.8\%); en la zona centro, $124(1.2 \%)$, en tanto que no fue posible precisar el lugar en que fueron secuestradas 3237 victimas (32\%). CNDH, "Informe especial de la comisión nacional de los derechos humanos sobre los casos de secuestro en contra de migrantes", México, 15 de junio, 2009, p. 13. [Consulta: 16 de junio, 2018]. Disponible en: http://www. cndh.org.mx/sites/all/doc/Informes/Especiales/2009_migra.pdf

55 Izcara Palacios, Simón Pedro, "Etiología del tráfico de migrantes en México: relevancia de los factores de atracción", Norteamérica, núm. 2, pp. 29-55.

${ }^{56}$ Martinez Quezada, José Álvaro y Ortega Ramirez, Adriana Sletza, "Internalización de normas Internacionales en materia de derechos de migrantes. El caso de Chiapas", Norteamérica, vol. 10, núm. 1, pp. 191-213.
} 
cadena de suministro de las empresas. Con ello, el marco mexicano es inocuo a las prácticas de explotación laboral.

\section{Conclusión}

México cuenta con un marco legal e internacional robusto para proteger los derechos laborales de los migrantes. No obstante, en razón del aumento del flujo migratorio y la falta de una política nacional coordinada y centrada en los derechos humanos, no han existido avances notables para dar eficacia a los mecanismos preventivos del trabajo forzoso y a las medidas de reparación para las víctimas. Es necesario, por tanto, reorganizar los planes y acciones del Gobierno federal que fomenten un eje nacional de prevención del trabajo forzado bajo las normativas del derecho internacional y, en especial, de las Convenciones de la Organización Internacional del Trabajo sobre trabajo forzado y esclavitud moderna.

Con ello se lograría una protección horizontal. Para lograrlo es necesario replantear la estrategia de prevención y castigo del trabajo forzado a nivel instituciones federales y locales (INM, FGR, Secretaría de Gobernación, gobiernos estatales, procuradurias y defensorias de derechos humanos locales) para tener acciones preventivas de explotación laboral y de otros tipos a favor de mujeres, niñas, niños, grupos indígenas, migrantes y desplazados forzados.

Esta visión multidimensional es la que en el ámbito internacional ha funcionado. Se advierte que el trabajo forzado demanda acciones multidimensionales a través de la legislación nacional y de creación de cuerpos especializados de monitoreo en instituciones administrativas que supervisen, sobre todo, el proceso de producción y el consumo de las empresas de bienes y servicios. Tal es el caso de Inglaterra, que ha logrado proteger los derechos de trabajadores migrantes frente a actos de trabajo forzado y esclavitud moderna. Esto, sin embargo, ha significado un cambio total de política pública y revisión integral de las prácticas empresariales, bajo la perspectiva de derechos humanos en sus cadenas de suministro y producción.

En cuanto a la jurisprudencia de las cortes nacionales y regionales, podemos concluir que las vías procesales de protección incluyen procedimientos civiles, del derecho penal y mecanismos de derechos humanos, ya que tanto el trabajo forzado como la esclavitud son sancionadas por disposiciones laborales, civiles, contractuales, empresariales y de derechos humanos de fuente internacional. Los casos de trabajo forzado de migrantes en Estados Unidos e Inglaterra nos muestran que, a través de la legislación civil, también se puede someter a juicio la acción ilícita de los particulares, mediante acciones de reparación de daños. 
Dentro del enfoque jurisprudencial de derechos humanos, destaca la vertebración del derecho internacional y regional en la Corte Interamericana. En la sentencia Brasil Verde vs. Brasil se sometió a juicio la discriminación histórica de los esclavos modernos. La metodología de la Corte IDH fue multinivel, usando todo el marco internacional y regional de derechos humanos con valor vinculante. El mayor logro es que el caso impulsó la creación de planes, programas y legislación en Brasil para erradicar el trabajo esclavo, mediante cambios administrativos, legislativos e institucionales para monitorear el cumplimiento de las normas sobre el trabajo esclavo en Brasil. En el caso de México, y quizá por las graves violaciones a la vida e integridad de los migrantes, la jurisprudencia no se ha ocupado del trabajo forzado como un tema específico. Se esperaría que, mediante mecanismos laborales, quejas ante la CNDH o juicios de amparo, los tribunales y otras instituciones puedan fijar las directrices que den vida a las disposiciones internacionales vigentes que prevengan y sancionen el trabajo forzado de migrantes.

\section{Referencias}

CIDH (Comisión Interamericana de Derechos Humanos), "Derechos humanos de migrantes, refugiados, apátridas, víctimas de trata de personas y desplazados internos: Normas y Estándares del Sistema Interamericano de Derechos Humanos”, 2015. [Consulta: 24 de septiembre, 2018]. Disponible en: http://www.oas.org/es/cidh/ informes/pdfs/movilidadhumana.pdf

CIDH (Comisión Interamericana de Derechos Humanos), “Informe N 51/96. Decisión de la Comisión en cuanto al mérito del caso 10.675", 13 de marzo de 1997.

Comisión Nacional de Derechos Humanos, Diagnóstico sobre la situación de la Trata de Personas en México, México, Comisión Nacional de Derechos Humanos, 2019. CNDH, "Informe especial de la comisión nacional de los derechos humanos sobre los casos de secuestro en contra de migrantes", México, 15 de junio, 2009, p. 13. [Consulta: 16 de junio, 2018]. Disponible en: http://www.cndh.org.mx/sites/all/ doc/Informes/Especiales/2009_migra.pdf

Consejo de Derechos Humanos de las Naciones Unidas (CDHNu), "Informe del Relator Especial sobre los derechos humanos de los migrantes sobre una agenda 2035 para facilitar la movilidad humana A/HRC/35/25”, 28 de abril, 2017.

Consejo de Europa, Convención Europea de Derechos Humanos, 4 de noviembre de 1950.

CorRIE, Karen, "Could the International Criminal Court Strategically Prosecute Modern Day Slavery?”, Journal of International Criminal Justice, vol. 14, núm. 2. Corte IDH (Corte Interamericana de Derechos Humanos), Caso Masacre de Mapiripán vs. Colombia, Serie C, núm. 134, Sentencia de 15 de septiembre de 2005. 
Corte IDH (Corte Interamericana de Derechos Humanos), Caso Tibi vs. Ecuador,

Excepciones Preliminares, Fondo, Reparaciones y Costas, Serie C, núm. 114, Sentencia de 7 de septiembre de 2004.

Corte IDH (Corte Interamericana de Derechos Humanos), Caso Maritza Urrutia vs.

Guatemala, Fondo, Reparaciones y Costas, Serie C, núm. 103, Sentencia de 27 de noviembre de 2003.

Corte IDH (Corte Interamericana de Derechos Humanos), Opinión Consultiva OC-18/03,

Condición jurídica y derechos de los migrantes indocumentados, serie A, núm. 18,

17 de septiembre, 2003.

Corte IDH (Corte Interamericana de Derechos Humanos), Hacienda Brasil Verde vs.

Brasil, Excepciones Preliminares, Fondo, Reparaciones y Costas, Serie C, núm. 318, sentencia de 20 de octubre, 2016.

Delgado Carbajal, Baruch y Bernal Ballesteros, María José, Catálogo para la calificación de violaciones a derechos humanos, Toluca, Comisión de Derechos Humanos del Estado de México, 2016.

“Directiva 2011/36/UE del Parlamento Europeo y del Consejo de 5 abril de 2011", Diario Oficial de la Unión Europea. [Consulta: 22 de julio, 2018]. Disponible en: https://eur-lex.europa.eu/legal-content/ES/TXT/PDF/?uri=CELEX:32011L0036 etfrom $=\mathrm{HU}$

Embajada y Consulado de los Estados Unidos en México, "Reporte sobre Trata de Personas 2019, Recomendaciones priorizadas”, US Embassy. [Consulta: 23 de agosto, 2019]. Disponible en: https://mx.usembassy.gov/es/our-relationship-es/ reportes-oficiales/reporte-sobre-trafico-de-personas/

European Commission, "Sustainable and responsible supply chains", European Comission. [Consulta: 23 de agosto, 2019]. Disponible en: https://ec.europa. eu/europeaid/sectors/economic-growth/private-sector-development/ sustainable-and-responsible-supply-chains_en

Gardner, Alison, “An Idea Whose Time Has Come? Modern Slavery, Multiple Streams Approach and Multilayer Policy Implementation”, Journal of Human Rights Practice, núm. 10.

Global Slavery Index, “Americas Report 2018”, Global Slavery Index. [Consulta: 14 de agosto, 2018]. Disponible en: https://www.globalslaveryindex.org/2018/findings/ regional-analysis/americas/

Home Secretary, "Transparency in Supply Chains etc. A practical guide 2017", Home Secretary. [Consulta: 14 de agosto, 2018]. Disponible en: https://assets.publishing. service.gov.uk/government/uploads/system/uploads/attachment_data/file/649906/ Transparency_in_Supply_Chains_A_Practical_Guide_2017.pdf

Izcara Palacios, Simón Pedro, "Etiología del tráfico de migrantes en México: relevancia de los factores de atracción", Norteamérica, núm. 2.

King’s Bench Court, Somerset v. Stewart, Londres, Trinity Term, 22 de junio, 1772. 
Martínez Quezada, José Álvaro y Ortega Ramírez, Adriana Sletza, “Internalización de normas Internacionales en materia de derechos de migrantes. El caso de Chiapas”, Norteamérica, vol. 10, núm. 1.

“Modern Slavery Act 2015, parts I, 2, 3, 4, 5 y 6”, House of Commons. [Consulta: 4 de octubre, 2018]. Disponible en: http://www.legislation.gov.uk/ukpga/2015/30/ contents/enacted

Morales SÁnchez, Julieta, Derechos de los migrantes en el Sistema Interamericano de Derechos Humanos, México, Comisión Nacional de los Derechos Humanos, 2015. Nottingham Crown Court, Case T20167397, (12 September 2017), (the Rooney family case).

OEA (Organization of American States), Captive communities: situation of the Guarani indigenous people and contemporary forms of slavery in the Bolivian Chaco, OEA, 24 de diciembre, 2009.

Oficina del Alto Comisionado de Naciones Unidas y Tribunal Superior de Justicia del Distrito Federal, Derecho Internacional de los Derechos Humanos: normatividad, jurisprudencia y doctrina de los Sistemas Universal e Interamericano, México, Alto Comisionado de Naciones Unidas - Tribunal Superior de Justicia del Distrito Federal, 2012.

OIM (onu Migración), "Reporte de flujos migratorios en Centroamérica, Norteamérica y el Caribe No. 6”, San José, Costa Rica, orm. [Consulta: 23 de agosto, 2019]. Disponible en: https://reliefweb.int/sites/reliefweb.int/files/resources/SITREP\%20 6\%20-020espanol\%20-\%20web.pdf

oNU (Organización de las Naciones Unidas), "Informe del Relator Especial sobre los derechos humanos de los migrantes A/71/285”, 4 de agosto de 2016.

onu, Principios Rectores sobre las Empresas y los Derechos Humanos, Ginebra, onu, 2011. огт (Organización Internacional del Trabajo), "Esclavitud moderna y trabajo infantil”, disponible en: https://www.ilo.org/global/about-the-ilo/newsroom/news/ WCMS_574731/lang--es/index.htm [Consulta: 4 de octubre, 2018].

оाт (Organización Internacional del Trabajo), "Estimación Mundial sobre el trabajo infantil y la esclavitud moderna de 2017. Hoja de Datos Regional de las Américas”, Ginebra, оाт, 2017.

Ripoll, Alejandra, "Colombia: Semillero para la trata de personas", Revista de relaciones internacionales, estrategia y seguridad, vol. 3, núm. 1.

Ruiz Moreno, Ángel Guillermo, "El derecho humano al trabajo de los migrantes", Revista Latinoamericana de Derecho Social, vol. 22.

Secretaría del Trabajo y Previsión Social, "Protocolo de Inspección para Prevenir y Detectar la Trata de personas en los Centros de Trabajo”, México, Secretaría del Trabajo y Previsión Social, 2017. [Consulta: 23 de agosto, 2019]. Disponible en: https://www.gob.mx/cms/uploads/attachment/file/200998/Protocolo_Trata_en_ centros_de_trabajo.pdf 
scJN (Suprema Corte de Justicia de la Nación), “Amparo directo 275/2017”, Noveno

Tribunal Colegiado en Materia Penal del Primer Circuito.

scjN (Suprema Corte de Justicia de la Nación), “Amparo directo en revisión 5770/2015”,

Primera Sala de la Suprema Corte de Justicia de la Nación.

Silva García, Fernando, Jurisprudencia Interamericana sobre Derechos Humanos.

Criterios esenciales, México, Tirant lo Blanch, 2016.

Swepston, LeE, "Forced and Compulsory Labour in International Human Rights Law", working paper, Suiza, International Labour Organization, 2014.

TEDH (Tribunal Europeo de Derechos Humanos), Chowdury y otros vs. Grecia (Application no. 21884/15), sentencia del 30 de marzo, 2017.

TEDH (Tribunal Europeo de Derechos Humanos), C. N. vs. Reino Unido (Application no. 4239/08), sentencia del 13 de febrero, 2013.

TEDH (Tribunal Europeo de Derechos Humanos), Rantsev v. Chipre \& Rusia (Application no. 25965/04), sentencia del 7 de enero, 2010.

TEDH (Tribunal Europeo de Derechos Humanos), Siliadin $v$. France (Application no. 73316/01), sentencia del 26 de octubre, 2005.

The Supreme Court of the United Kingdom, Reyes v. Al-Malki and another [2017] UKSC 61.

US Supreme Court, United States et al. vs. Texas et al., caso 15-674. Argumentos orales del 18 de abril, 2016, intervención del Juez Alito.

Vladislava, Stoyanova, Conceptual Limits and States' Positive Obligations in European Law, Human Trafficking and Slavery Reconsidered, Cambridge, Cambridge University Press, 2017.

Webb, Derek, "The Somerset effect: Parsing Lord Manfield's. Words on Slavery in Nineteenth-Century America”, Law and History Review, vol. 32, núm. 3.

Wilkinson, Daniel, "México desplegará su Guardia Nacional para enfrentar a familias migrantes”, Human Rights Watch. [Consulta: 23 de agosto, 2019]. Disponible en: https://www.hrw.org/es/news/2019/06/12/ mexico-desplegara-su-guardia-nacional-para-enfrentar-familias-migrantes 